\title{
Search Delegation, Synthesists and Expertise on Social Media
}

\author{
Paul Matthews \\ Department of Computer Science and Creative Technologies, \\ University of the West of England, United Kingdom \\ paul2.matthews@uwe.ac.uk
}

\begin{abstract}
Background. Social media often adds a layer of intermediation between sources and information consumer, with users outsourcing some of the information work to others. Social media "synthesists" have been identified as a group of volunteer information providers fulfilling this role.

Approach. Through a review of evidence from philosophy, information science and knowledge management, this paper explores the implications of cognitive outsourcing, presents quality standards for synthesis and asks how well synthesists meet these. In the process, the role of intermediary is discussed, along with the non-specialist status of the synthesist.

Results. Findings show that social media synthesists fulfil a useful role and that their importance in terms of knowledge translation is clear. While their synthesis quality may fall far short of LIS standards, there are a number of ways that some quality issues can be addressed, including the involvement of the information profession itself on the same social platforms.

Contribution. Through a comparison of synthesis best practice with current informal information behaviour on social media, the paper draws attention to quality issues and new opportunities to address them. This represents an attempt to identify ways to bridge formal and emerging, informal information markets.
\end{abstract}

\section{INTRODUCTION}

"It is somewhat ironic that we live in a culture that rewards specialization, yet most specialized scientific and professional knowledge is built on syntheses of diverse data and ideas." (Gazan, 2006).

Social media is blurring the boundaries between socialising and information seeking. Increasingly, users will consider routing queries through social platforms in addition to the more traditional search engines. The advantages of such routing include the opportunity for knowledge to be translated into a more understandable form and for some of the cognitive work to be "friendsourced" or offloaded to connections within the network or community. While there may be substantial benefits to the searcher from such an approach-including time savings and overall efficacy - there are also potential costs in terms of social capital depletion and a loss of a direct engagement with sources.

Information seeking models have tended to focus on the individual and their engagement with information, though more recently social and collaborative models have been proposed (Evans \& Chi, 2008). However these models tend to look at more direct 
communication and collaboration with others during the various stages of the search process rather than the phenomenon of "social reference," where information gathering is delegated to possibly unknown persons and may be quite far removed in time and space from the primary information seeking activity itself (Shachaf, 2010).

From a library and information service perspective, an important question has been what sort of challenge information social reference provides to traditional knowledge services. While quality between platforms and the contributions of online users is clearly variable (Fichman, 2011), collaboratively sourced answers on some platforms may be as good or even better than traditional library services when measured against service quality criteria which include responsiveness, reliability and assurance (Shachaf, 2009). This needs to be balanced against what are often distinctly different motivations of social community members to contribute answers in comparison to the raison d'etre of "official" information support services. Not only are contributions often spurred on by the (selfish) prospect of increased online reputation score, posts and associated citations may also be used to support persuasion, therefore focusing on one-sided arguments on controversial topics (Savolainen, 2013).

From the provider side then, social reference needs to be scrutinised and situated in terms of quality. On the receiver side, information seeking, particularly by less experienced students, is known to be often driven by expediency and convenience (Connaway, Dickey \& Radford, 2011). This can lead to a seeker being satisfied with the first source that seems to fulfil requirements, without a deeper acknowledgement of the basis for such satisfaction. This has been dubbed "information naivety" or the ungrounded belief that information is comprehensive (Brody, 2008). The converse - and a normative goal — is a deep, iterative engagement with the extant knowledge on a topic, leading to an expansion of information horizons (Boell \& Cecez-Kecmanovic, 2014).

The delegation of information sourcing and synthesis is an important consideration in the study of online information behaviour. This applies not only to those affected directly by the original informational exchange, as the online resource created has archival value to future perhaps more passive users (Harper, Moy \& Konstan, 2009). So the phenomenon raises questions. To what extent, for example, is social reference and synthesis potentially damaging to knowledge-seeking ideals? What sort of quality of synthesis do users on social platforms provide? How do these measure up against received quality standards for synthesis? This paper attempts to evaluate the available evidence in this nascent research area, first by looking at an epistemological view of social knowledge, then at standards for synthesis evaluation, then by further exploring the concepts of intermediation and of the expert relationship. It will go on to discuss the type of users who are providing syntheses, and to explore the contrast in system provision for synthesis behaviour across social platforms. Finally, design and user training recommendations are given that might help to increase the quality of social synthesis in addition to receiver awareness of their limitations.

\section{EPISTEMOLOGICAL EVALUATION}

The distribution and delegation of knowledge activities have been discussed recently within epistemology, the philosophy of knowledge. Those seeking to delegate information gathering are effectively engaging in a kind of cognitive outsourcing (Ahlstrom-Vij, 2014). AhlstromVij notes that from a quality-of-knowledge perspective, such behaviour does not automatically constitute a bad move. While issues of unreliability of testimony, gullibility and lack of intellectual autonomy all pose threats to such outsourcing, leading to reliable knowledge, Ahlstrom-Vij argues that these problems can be redressed individually through 
improving an agent's awareness of bias and ability to discriminate reliable sources. Furthermore, while dependency and lack of autonomy appear to be negatively loaded concepts, they may in fact be both necessary and desirable in a world where knowledge is necessarily distributed socially. Indeed, in an analysis of cases of distributed cognition, Green (2014) notes that in many knowledge-seeking enterprises - science being the classic casedistribution of knowledge is essential. If remote actors are reliable then there is no reason that knowledge gained should not be as valid as that generated within a single individual.

Other social epistemologists have stressed the importance of identity and authority in knowledge seeking and assessment (Fricker, 2007; Origgi, 2012). While the identification and placing of trust in reputable and authoritative individuals usually helps us to minimise error and maximise efficiency, misplaced trust or the side-lining of those with valid knowledge can be particularly damaging. With online interaction, we need to be especially careful not to unquestioningly conflate real-world reputation signals with online proxies such as accumulated up-votes or the number of posts contributed (Matthews \& Simon, 2012).

In terms of the philosophical basis to search delegation then, there is some agreement that there is nothing wrong with this in principle. That said, the information seeker needs to bear responsibility for the assessment and selection of the testimony received and be particularly vigilant where there is a risk of bias or of a misconstrual of authority. Part of this should include an assessment of what makes a delegated answer-another's synthesis — of high quality.

\section{WHAT MAKES FOR GOOD SYNTHESIS?}

It is helpful to establish quality standards for syntheses from various academic communities, before going on to investigate the types of syntheses found on social media platforms. The most common criteria for a good synthesis are that it is systematic, balanced, objective, representative, thorough, based on valid, authoritative sources (and these are referenced), and that it identifies knowledge gaps (Boell \& Cecez-Kecmanovic, 2014; Goldschmit, 1986). Ideally it should give a broad perspective and often outline the historic development of a topic (Green, Johnson, \& Adams, 2006).

Synthesis in LIS has been further defined as "the systematic gathering of research findings on a defined topic for use by a specific audience for a given purpose, the systematic assessment of their validity; and the presentation of valid findings in a form useful to the intended audience" (Goldschmit, 1986, p. 217). A synthesis represents a unified, integrated collection of the current state of information on a given topic. The overarching objective may be seen as "trash compacting," reducing content to a manageable size, or "panning for gold," extracting the most salient and relevant points from a corpus (Goldschmit, 1986).

Topic definition is an important first step in conducting a synthesis, in order to determine exactly what information is needed and to understand the audience for the results (Goldschmit, 1986).

A synthesis often has a special meaning in the research community, being used to designate a study that draws together findings from a group of related studies (though this may be more accurately described as metasynthesis). The process for conducting a synthesis is to conduct a search using a set of keywords within named databases, to apply qualification and quality criteria to the selection of papers and to have a well-described method for aggregating and comparing their results (Urquhart, 2010). A key aspect here is the transparency and hence the replicability of the method (Boell \& Cecez-Kecmanovic, 2014), in 
that the reader is clear on the process used for finding and sifting information and then presenting it in a digestible, clear and logical form.

While synthesis aims at presenting findings, the preceding process of literature review can be viewed as one of understanding, with a hermeneutical circle being formed from the process of analysis and interpretation, within which is the smaller circle of source search and acquisition. The process is strongly iterative as understanding is broadened and deepened as each new text is encountered (Boell \& Cecez-Kecmanovic, 2014). The quality of a review depends on the quality of all the components within the hermeneutical circle - acquiring, mapping/classification and argument development.

So the LIS profession has helped to shape and define the concept of a synthesis. We will see that much social media synthesis behaviour in general falls far short of the kind of work described here, although the audience tailoring aspect may be strongest, and there are other social part-compensations. What is certainly clear is that, with the rise of social media, there has been a reduction in the barriers to entry and an increase in the opportunities for a range of parties to contribute to synthesis creation.

\section{CONCEPTS OF SPECIALIST AND AMATEUR}

A core concern in the discourse on social referencing has been the involvement of amateurs and novices in contrast to professionals, specialists and experts. Some have sought to draw a clear distinction here between "traditional" information services and this new social collaborative behaviour. For Koltay (2011b), for instance "it is unrealistic to harness to a substantial effect the wisdom of the crowd for producing professional and scholarly information." Professionals are seen to have need of higher standards of reliability and validity (Koltay, 2011a). Koltay is strongly of the view that amateur and professional needs differ with the former being best served by social media. Amateurs are seen to predominate on the social web, where critical thinking and thoughtful selection of content is not obvious (Koltay, 2011a). That said, it would seem that Koltay is not distinguishing between primary content creation and content synthesis in these opinions.

But some of these misgivings over "amateurish" contributions are misplaced and the line between the amateur and professional is not so clear. Brabham (2012), for instance, questions the prevailing discourse on amateurs in crowdsourcing, noting that many participants have some knowledge or experience and are prepared to devote time and a level of attention to detail on par with experts or professionals. Similarly in Shachaf's (2009) study, Wikipedia Reference Desk workers were mostly topic experts, though not much detail was given about how they were classed as expert.

And there are valid questions over the benefits of expertise. For instance, experts may be less able to elaborate ideas in a way that makes them accessible (Shachaf, 2009). The skills needed for effective synthesis may lie more with learners than with domain experts: "An expert may have the advantage of being more adept at finding sources in her field of study, but a high school student quite often will play a greater role in shaping Wikipedia simply because she has better researching and summarizing skills, having been brought up in a connected world" (McGrady, 2009).

Following on from the above, then, we might identify a skill of synthesis creation which transcends traditional conceptions of what it takes to be a subject matter specialist or expert. These skills are not only associated with engagement with the literature and subject knowledge but also the way in which it is delivered. 
Table 1. Comparison of knowledge broker roles with social media synthesists

Role of Knowledge Brokers (Fisher, 2010) Social Synthesists?

Enabling and maintaining access to information

Making information more digestible for audiences

Creating demand for information/generating cultures of information use

Supporting marginalized voices to be heard

Creating alternative framings of issues

Connecting spheres of action

Enabling accountability, e.g. enabling groups to hold decision makers to account.
Partly, through locating and annotating sources (though these are usually also accessible to the receiver)

Yes, through synthesis and knowledge translation to community-oriented language

Partly, through

enforcement/embodiment/improvement of community norms

Slightly?

Partly, platform-dependent?

Possibly, occasionally

Out of scope?

\section{INTERMEDIATION}

The Web 2.0 paradigm has usually been associated with disintermediation, with the removal (without replacement) of the traditional gatekeepers to information (Brody, 2008). But information intermediaries ("infomediaries") have been shown to come forward within communities and services to fulfil parts of these roles.

Good infomediaries are embedded in the information context, and are capable of building trust and increasing the relevance and accessibility of information. Personal characteristics should include intellectual and affective empathy, with increasing need for intellectual empathy as users become more advanced (Ramirez, Parthasarathy \& Gordon, 2013).

Intermediaries' level of involvement lies on a continuum between merely access providers to supporters of decision making. While information intermediaries enable access to information from multiple sources, knowledge intermediaries or translators help to make sense of it and to apply it (Fisher, 2010).

There seems to be a good fit between some providers of social reference and conceptions of knowledge intermediaries. The comparison is useful because it also helps to indicate where social reference providers may be incentivised and encouraged to improve their work or raise their aspirations. Table 1 summarises the conception of a knowledge broker with my analysis of how well social media synthesists fulfil them.

So social synthesists have at least the potential to play the role of infomediaries and knowledge brokers. But to what extent are such people actually present on social media services?

\section{WHO ARE THE SYNTHESISTS?}

With the rise of online communities, an emerging role has been that of the online moderator or power user and it is these users who may be the most effective synthesisers and knowledge 
Table 2. A comparison of specialists and synthesists (Gazan, 2006)

\begin{tabular}{ll}
\hline Specialists & Synthesists \\
\hline Give information & Receive information \\
Use specialized terms & Translate specialized terms \\
Can't articulate the roles of others & Can articulate the roles of others \\
Strong sense of role & Role more flexible \\
Fewer ties in social network & More centrality in social network \\
Work is featured & Work "under the radar" \\
\hline
\end{tabular}

brokers. A power user may be officially designated, or may simply emerge based on the activity and status of the user within the community. Some online platforms use reputation points to reward users with elevated permissions to manage others' posts. Among the many attributes of community mavens such as these are the willingness to devote time to the community, a good knowledge of the users and a knowledge of the platform. Importantly, they will show good communication skills, and being within the community will be able to use language that will be understandable to members. Such individuals may only represent a very small proportion of the total population of users (e.g., Cobb, Graham, \& Abrams, 2010). "Content weaving" has been noted as an important function of such individuals, who are able to summarise information from within and outside the community in succinct and wellcurated posts (Matthews \& Stephens, 2010).

But synthesis behaviour is found in "regular" users too. Gazan (2006) sampled nearly 10,000 answers on the social question-answering site Answerbag. He found that $37 \%$ of the users providing the answers could be defined as pure specialists or synthesists, with the specialists' answers rated as $92 \%$ useful — the site's average — whereas synthesists' answers were ranked more highly at $94 \%$ useful. Gazan's (idealised and conceptual) characterisation of these provider types are indicated in Table 2.

Gazan's distinction between contributor types, albeit to seen as extremes on a spectrum, seems to have a reasonable evidence base and to hold across platforms. Wikipedia editors are frequently synthesists with a high level of ability to integrate information sources but without first-hand domain expertise. In one Wikipedians study, such editors were 20-50 years old with a range of occupations, including students, blue-collar workers, managers and computer specialists. Many Wikipedians are active across topics, though some confine themselves to a narrower range. They have been dubbed "janitors" as, in addition to page authoring, they do a lot of housekeeping work to keep information consistent and free from vandalism (Sundin, 2011, p. 858).

Importantly, power users are by no means uniformly nonpartisan. Iba, Nemoto, Peters and Gloor (2010) applied network analysis to Wikipedia editing behaviour and noted two types of prolific, generalist editor or "coolfarmer"- those seeking to strike a balance between opposing views and remain neutral (the mediators) and those with a strong view on one side of a debate (the zealots). The same holds true on social question-answering platforms, with answerers often motivated by opinion and the desire to influence others (Savolainen, 2013).

\section{INFORMATION SEEKING PATTERNS BY PLATFORM TYPE AND SYNTHESIST AFFORDANCE}

The social media umbrella contains a diverse array of platforms and services, which vary in terms of openness, network structure and the extent to which they support information 
aggregation and asking questions. Different social media platforms are seen to have quite idiosyncratic benefits that influence decisions to route queries in a particular way (OeldorfHirsch, Hecht, Morris, Teevan \& Gergle, 2014). Indeed we can identify a continuum with general purpose social networking applications at one end, and purpose built questionanswering platforms and wikis at the other.

Platforms such as Facebook may be rarely used for informational search. Of 106 individuals studied, for instance, only two instances of factual information seeking were noted on Facebook (Gray, Ellison, Vitak \& Lampe, 2013). More were rhetorical or opinion-based. Because such networks often include real-world friends and connections present stronger ties, there may be a reluctance to burden others with informational requests (Rzeszotarski \& Morris, 2014).

Social question-answering (QA) sites, by contrast, are a more natural home for synthesists. Here, interaction is between users usually unknown to each other, connected less by friendship and more by domains of interest. Questions posted by members of the community often receive answers very quickly, and can rate or "accept them" according to the extent that they fulfil the information need.

For QA sites, synthesist behaviour is not always transparent. Of 575 answers extracted from Yahoo Answers in one study, only 5\% contained references (Shah \& Pomerantz, 2010). But it is very likely that answer providers were often using external sources without quoting them. In a larger study of Yahoo Answers, Oh, Oh and Shah (2008)found that 7.68\% of 101,985 answers included source information, but of these $56 \%$ were human sourcespersonal knowledge or experience - and 38\% were Internet sources, with Wikipedia occurring in $6 \%$ if these.

Rather than being used to illustrate a balanced answer, reference use within certain topics is used to persuade toward a particular view. For the topic of climate change on Yahoo Answers, 657 answers contained 100 references to various information sources, 90\% being online sources and 3\% books. Only 34\% of these references were classed as scientific (Savolainen, 2013).

Wikipedia represents something of a social gold-standard in terms of referencing, driven by its overt policies of verifiability and neutral point of view (Sundin, 2011). Fichman (2011) looked at answer quality across two social QA sites and two wiki sites (Wikipedia and Wiki Answers), finding her measure of "verifiability" - whether a page contained a link to sources - to be $43 \%$ and $25 \%$ in the QA sites, but $76 \%$ on Wikipedia. On Wikipedia, reference sourcing is an integral part of the editor's role and helps to establish trust. The availability of sources may determine the choice of articles to write, rather than the other way around. A hierarchy of sources is used and referred to by editors, who may seek to improve articles by raising the source quality (Sundin, 2011).

\section{CONCLUSIONS AND RECOMMENDATIONS}

We have seen that, perhaps despite misgivings, the case for socially-sourced synthesis is quite strong, and addresses in particular the need for knowledge translation that is seen to be a core part of knowledge brokerage. We should also recognise its necessity given the social distribution of knowledge. While the common conception has been that subject experts provide the best sources, there is quite good evidence that conscientious synthesists can do at least as well and often better. We should thus see our ideal synthesists along the lines of Schutz's (1946) "analyst" type of informant —one who shares your system of relevance and has collected and organised information on the topic of interest (Wilson, 2002). 
Social media has the important potential for a heterogeneous and diverse range of views to come together, enriching the synthesis for the user. This "polyvocal" structure seems to be more explicit than in traditional sources, even if they are themselves synthesised. The collaborative nature of edited answers on Wikipedia Reference Desk, for instance, may explain their potential for improvement over a traditional reference interview (Shachaf, 2009). In this way balance and coverage may be achieved not through any single informant, but through their plurality.

\section{Improvements to Technical and Social Systems}

How might social applications be improved to support better quality synthesis? Approaches need to encompass discrete aspects of the socio-technical system: the platform design and functionality, the community norms, the community membership and the content produced by these members.

Given that quality criteria for syntheses are relatively easy to derive, it would be possible to improve the rating and review methods on social sites to encourage features such as balance, thoroughness and transparency. The latter might be better recorded through the use of additional text fields describing how answers were researched and constructed. The relative success of the Wikipedia policies shows that there is significant potential to raise awareness of these ideals.

Also in terms of system design, it has been observed that the retrieval of sources might be combined with the answer platform itself. Through their studies of social and collaborative search, authors have suggested a melding of the functions of search platforms and social media (Oeldorf-Hirsch, Hecht, Morris, Teevan \& Gergle, 2014). This could conceivably be brought to bear at various different stages in the information seeking process.

We have seen that the wiki provides strong support to synthesists. This proven capacity has led to their inclusion within QA platforms such as Quora and WikiAnswers, though on Quora the function seems to be under-utilised.

There might also be some further improvement of social QA threads picked up by the search engines. Given the prominence of QA resources in result pages, a quality filtering process (human or machine driven) might improve the quality of resources encountered (Shah \& Kitzie, 2012).

\section{Interventions by Information Professionals}

There is great potential for information professionals, with their specialist sourcing, referencing and synthesising abilities, to contribute to social media both formally and informally. In recent years, for example, librarians and archivists have contributed to Wikipedia through participation in "editathons" and the "Wikipedia Loves Libraries" initiative (SinhaRoy, 2011; Wikipedia, 2014).

For social question answering, Luo (2014) describes the "Slam the Boards" initiative whereby librarians regularly contribute answers to QA services (mostly Yahoo Answers), embodying best practice in terms of referencing and balance. A key motivation for this is the promotion of library services, though many participants also consider it to be interesting and professionally useful. Luo notes that participants rarely have explicit institutional backing for the activity, or if they do then it limits their time greatly. Interestingly, Luo notes the possibility for librarian participants on QA to turn opinion-oriented questions into informational ones, thereby providing askers with a possible evidence base or information support to their question. 
Another question is whether existing library online reference services should more closely resemble online QA. Shah and Kitzie (2012) compared virtual reference and social question answering sites and noted that while the former often provide higher quality and better referenced answers, the latter have undeniable advantages of scale, engagement and responsiveness. A question is therefore whether virtual reference services should be more like social QA platforms, or even be replaced by them. There seem to be many aspects in common between the answer evaluation criteria employed by professionals and amateurs. But while experts might value a comprehensive and well-referenced answer, students value speed and social aspects more, indicating that virtual reference services need to more closely resemble social QA, rather than vice-versa, even if only in the time to a first response (Shah \& Kitzie, 2012).

So there seems to be an increasing interest and ability for information specialists to help to raise synthesis standards on informational social media. Perhaps more managementlevel support for such initiatives would be helpful in making this part of formal duties or active projects.

\section{FURTHER WORK NEEDED}

Having established that, from the epistemological perspective, there is nothing wrong in principle with cognitive outsourcing, it will be instructive to assemble psychological and educational evidence to confirm or refute any effects of information dependency and reduction in intellectual autonomy that might result from relying too much on this route of information gathering. Conversely, it may prove that the social capital benefits from successful social sourcing outweigh any such intellectual costs.

Additionally, longitudinal studies following from some of the interventions described above (for example, better rating systems for social syntheses) would also help establish whether such feedback can lead to lasting effects on the quality of synthesis work and help it to approach the kind of ideal that LIS professionals strive for.

\section{REFERENCES}

Ahlstrom-Vij, K. (2014). What's the problem with cognitive outsourcing? Unpublished manuscript.

Boell, S., \& Cecez-Kecmanovic, D. (2014). A hermeneutic approach for conducting literature reviews and literature searches. Communications of the Association for Information Systems, 34, article 12. Retrieved from htp://aisel.aisnet.org/cais/vol34/iss1/12

Brabham, D. C. (2012). The myth of amateur crowds. Information, Communication \& Society, 15(3), 394-410.

Brody, R. (2008). Credibility and information naiveté in socially networked information. In IEEE International Symposium on Technology and Society (ISTAS) 2008 (pp. 1-3). New York: IEEE.

Cobb, N. K., Graham, A. L., \& Abrams, D. B. (2010). Social network structure of a large online community for smoking cessation. American Journal of Public Health, 100(7), 1282-1289.

Connaway, L., Dickey, T., \& Radford, M. (2011). "If it is too inconvenient, I'm not going after it": Convenience as a critical factor in information-seeking behaviors. Library and Information Science Research, 33, 179-190. 
Evans, B. M., \& Chi, E. H. (2008). Towards a model of understanding social search. In Proceedings of the 2008 ACM Conference on Computer Supported Cooperative Work, San Diego, CA, USA (pp. 485-494). New York: ACM.

Fichman, P. (2011). A comparative assessment of answer quality on four question answering sites. Journal of Information Science, 37(5), 476-486.

Fisher, C. (2010). Knowledge brokering and intermediary concepts. Retrieved from http://www.knowledgebrokersforum.org/blogs/item/knowledge-brokering-andintermediary-concepts-e-discussion-analysis

Fricker, M. (2007). Epistemic injustice. power and the ethics of knowing. Oxford: Oxford University Press.

Gazan, R. (2006). Specialists and synthesists in a question answering community. Proceedings of the American Society for Information Science and Technology, 43(1), 110. Retrieved from http://eprints.rclis.org/bitstream/10760/8793/1/Gazan_Specialists.pdf

Goldschmit, P. G. (1986). Information synthesis-A practical guide. Health Services Research, 21(2), 215-237.

Gray, R., Ellison, N. B., Vitak, J., \& Lampe, C. (2013). Who wants to know? Question-asking and answering practices among facebook users. In Proceedings of the 2013 Conference on Computer Supported Cooperative Work, San Antonio, Texas, USA (pp. 1213-1224).

Green, A. (2014). Evaluating distributed cognition. Synthese, 191(1), 79-95.

Green, B. N., Johnson, C. D., \& Adams, A. (2006). Writing narrative literature reviews for peer-reviewed journals: Secrets of the trade. Journal of Chiropractic Medicine, 5(3), 101-117.

Harper, F. M., Moy, D., \& Konstan, J. A. (2009). Facts or friends?: Distinguishing informational and conversational questions in social Q\&A sites. In Proceedings of the SIGCHI Conference on Human Factors in Computing Systems, Boston, MA, USA (pp. 759-768). New York: ACM.

Iba, T., Nemoto, K., Peters, B., \& Gloor, P. A. (2010). Analyzing the creative editing behavior of wikipedia editors: Through dynamic social network analysis. Procedia Social and Behavioral Sciences, 2(4), 6441-6456.

Koltay, T. (2011a). Information literacy for amateurs and professionals: The potential of academic, special and public libraries. Library Review, 60(3), 246-257.

Koltay, T. (2011b). New media and literacies: Amateurs vs. professionals. First Monday, 16(1-3) Retrieved from: http://firstmonday.org/ojs/index.php/fm/article/view/3206/2748

Luo, L. (2014). Slam the boards: Librarians' outreach into social Q\&A sites. Internet Reference Services Quarterly, 19(1), 33-47.

Matthews, P., \& Simon, J. (2012). Evaluating and enriching online knowledge exchange: A socio-epistemological perspective. In A. A. Lazakidou, R. Sharda \& S. Voay (Eds.), Virtual communities, social networks and collaboration (pp. 35-59). New York: Springer. Retrieved from http://dx.doi.org/10.1007/978-1-4614-3634-8_3

Matthews, P., \& Stephens, R. (2010). Sociable knowledge sharing online: Philosophy, patterns and intervention. Aslib Proceedings, 62(6), 539-553. Retrieved from http://dx.doi.org/10.1108/00012531011089667

McGrady, R. (2009). Gaming against the greater good. First Monday, 14(2). Retrieved from http://firstmonday.org/article/view/2215/2091

Oeldorf-Hirsch, A., Hecht, B., Morris, M. R., Teevan, J., \& Gergle, D. (2014). To search or to ask: The routing of information needs between traditional search engines and social 
networks. In Proceedings of the 17th ACM Conference on Computer Supported Cooperative Work \& Social Computing, Baltimore, Maryland, USA (pp. 16-27). New York: ACM.

Oh, S., Oh, J. S., \& Shah, C. (2008). The use of information sources by internet users in answering questions. Proceedings of the American Society for Information Science and Technology, 45(1), 1-13.

Origgi, G. (2012). A social epistemology of reputation. Social Epistemology, 26(3-4), 399418.

Ramirez, R., Parthasarathy, B., \& Gordon, A. (2013). From infomediaries to infomediation at public access venues: Lessons from a 3-country study. In Proceedings of the Sixth International Conference on Information and Communication Technologies and Development: Full Papers - Volume 1, Cape Town, South Africa (pp. 124-132).

Rzeszotarski, J. M., \& Morris, M. R. (2014). Estimating the social costs of friendsourcing. In Proceedings of the SIGCHI Conference on Human Factors in Computing Systems, Toronto, Ontario, Canada (pp. 2735-2744). New York: ACM.

Savolainen, R. (2013). Strategies for justifying counter-arguments in Q\&A discussion. Journal of Information Science, 39(4), 544-556.

Schutz, A. (1946). The well-informed citizen: An essay on the social distribution of knowledge. Social Research, 13(4), 463-478. Retrieved from http://www.jstor.org/stable/40958880

Shachaf, P. (2009). The paradox of expertise: Is the wikipedia reference desk as good as your library? Journal of Documentation, 65(6), 977-996.

Shachaf, P. (2010). Social reference: Toward a unifying theory. Library \& Information Science Research, 32(1), 66-76.

Shah, C., \& Kitzie, V. (2012). Social Q\&A and virtual reference: Comparing apples and oranges with the help of experts and users. Journal of the American Society for Information Science and Technology, 63(10), 2020-2036.

Shah, C., \& Pomerantz, J. (2010). Evaluating and predicting answer quality in community QA. In Proceedings of the 33rd International ACM SIGIR Conference on Research and Development in Information Retrieval, Geneva, Switzerland (pp. 411-418). New York: ACM.

SinhaRoy, S. (2011). Libraries tap into the crowdsource. American Libraries, 42(11/12), 22 23.

Sundin, O. (2011). Janitors of knowledge: Constructing knowledge in the everyday life of wikipedia editors. Journal of Documentation, 67(5), 840-862. Retrieved from http://dx.doi.org/10.1108/00220411111164709

Urquhart, C. (2010). Systematic reviewing, meta-analysis and meta-synthesis for evidencebased library and information science. Information Research, 15(3), colis708. Retrieved from http://www.informationr.net/ir/15-3/colis7/colis708.html

Wikipedia. (2014). Wikipedia loves libraries. Retrieved December 1, 2014, from http://en.wikipedia.org/wiki/Wikipedia:Wikipedia_Loves_Libraries

Wilson, T. D. (2002). Alfred Schutz, phenomenology and research methodology for information behaviour research. Paper presented at ISIC4-Fourth International Conference on Information Seeking in Context, Universidade Lusiada, Lisbon, Portugal, September 11 to 13, 2002. Retrieved from http://www.informationr.net/tdw/publ/papers/schutz02.html 